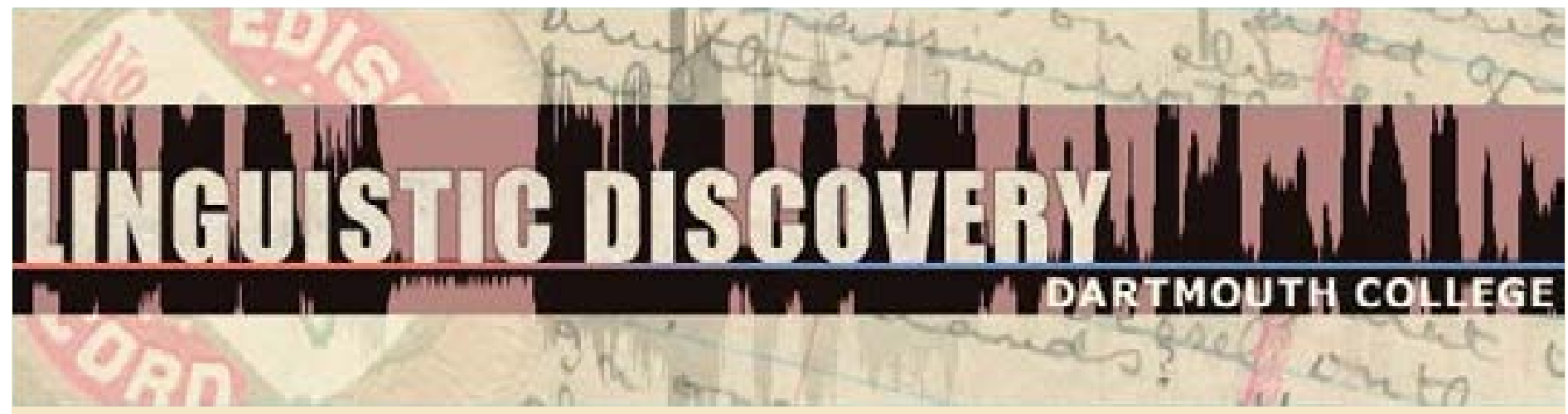

Volume 11 Issue 1 2013

\section{The Optional Use of Morphological Case}

Sander Lestrade

Radboud University of Nijmegen

University of Amsterdam

doi: $10.1349 / P S 1.1537-0852 . A .437$

url: http://journals.dartmouth.edu/cgi-bin/WebObjects/ Journals.woa/1/xmlpage/1/article/437
Linguistic Discovery

Published by the Dartmouth College Library Copyright to this article is held by the authors. ISSN 1537-0852 linguistic-discovery.dartmouth.edu 


\title{
The Optional Use of Morphological Case
}

\author{
Sander Lestrade
}

Radboud University of Nijmegen

University of Amsterdam

This paper provides a unified account of construction alternations in which case markers are involved, extending the traditional focus on the differential use of core case markers (DCM). Using an Optimality Theoretic framework, it is argued that the optional use of morphological case can be explained by the interaction of an economy and cooperativeness principle.

\section{Introduction}

Differential case marking (DCM) has mostly been studied for core cases, which mark the core arguments of a verb, i.e. the subject and object. ${ }^{1}$ As a result of this focus, DCM has accordingly been explained in terms of the communication of core argument structure only. For example, it has been proposed that case is used to keep apart the subject from the object, or to identify an unqualified performer of one of these functions (e.g., an involuntary agent). As will be shown in this paper, however, this type of DCM is only one instance of what seems to be a much more general phenomenon of case optionality for which a more general account can be provided.

Using an Optimality Theoretic framework, it will be proposed that the optional use of morphological case can be explained by the interaction of two well-known pragmatic principles only, namely economy and cooperativeness. The speaker tries to use the most economical expression from which the willing hearer can still be expected to derive the intended meaning by enriching the utterance with predictable information.

\section{Variation in Case Alternation}

In this section, a range of examples illustrating the optional use of case will be introduced. These examples will be discussed in more detail in later sections devoted to them specifically. For now, the purpose is to bring them together as instances of a more general phenomenon indeed (cf. Moravcsik 2009 for a similar overview; differently from her study, however, this paper will continue to provide a uniform account of the attested variation).

First consider some often cited examples of the optional use of core case. For Fore, it has been claimed that the use of ergative case on an agent is only necessary if without it word order and animacy hierarchies lead to the wrong interpretation. By default, the argument that is highest in animacy is interpreted as the subject; in case of a draw, the one who comes first is (Scott, 1978, 114-116). Thus, in (1) without the explicit marking of the opposite, the man is understood as acting on the pig.

Fore (Scott, 1978, 115-116)
a. Yaga:-wama
wá aegúye.
pig-ERG man 3SG.OBJ.hit.3SG.SU.IND

\footnotetext{
${ }^{1}$ Many thanks to the audience of the workshop Structural Alternations: Speaker and Hearer Perspectives (Groningen, August 2011) and to two anonymous reviewers for valuable comments that helped to improve this paper.
} 
'The pig attacks the man.'

b. Yaga: wá aegúye.

pig man 3SG.OBJ.hit.3SG.SU.IND

'The man kills the pig.'

As another well-known example of the optional use of core case consider the alternation in Hindi, in (2). Here, the general claim is that since objects are mostly nonspecific, they have to be marked explicitly for their role if they are not:

Hindi (de Hoop and Malchukov, 2008,576)
a. Wo ek laD.kaa dekhtaa hae
he one boy seeing is
'He sees a boy.'
b. Wo ek laD.ke-ko dekhtaa hae he one boy-ACC seeing is
'He sees the boy.'

As a result of the focus on examples such as these, in which case is used to mark core arguments, DCM has been explained in terms of the communication of verbal argument structure only. However, core case alternations are only one instance of what seems to be a much more general phenomenon, as the remainder of this section will show. In the next sections, it will be proposed that a uniform account of this variation can be given indeed.

As a first example of the broader range of DCM, consider the optionality of spatial case in Bukharian Uzbek:

Bukharian Uzbek (Aziz Djuraev, p.c.)

(3) $\quad$ biz bozor(-ga) borasizmi?
you market-DAT go
'Will you go to the marketplace?'

If the case marked object is a typical reference object, such as a marketplace, whose function is largely predictable from context, spatial case may be dropped.

Then, instead of alternating with a zero form as in all previous examples, a case may be in competition with a more elaborate form of expression. In (4), an example is given of the alternation between a spatial case form and an adpositional phrase.

Marathi (Pandharipande 1997, 340)
a. Tsor gharā-t s'irlā.
thief house-LOC entered
'The thief entered the house.' 

b. Tsor gharā-tSyā-àt s'irlā. thief house-POSS-in entered 'The thief entered the house.'

Also, we find alternations between different types of case. In (5), there is a alternation between core case and spatial case (building on an ergative stem) corresponding to a difference in volitionality.

Lezgian (Haspelmath 1993, 292)
a. Zamira-di get'e xana.
Zamira-ERG pot break.AOR
'Zamira broke the pot.'
b. Zamira-di-waj get'e xana.
Zamira-ERG-ABL pot break.AOR
'Zamira broke the pot accidentally/involuntarily.'

By the addition of ablative case, the Agent is marked as performing an act involuntarily.

Next, example (6) illustrates how the use of the ergative may depend on tense and aspect. In Hindi, Ergative case is used in perfective but not in imperfective aspect.

Urdu/Hindi (Woolford 2007)
a. Ram gari cala-yi (hai).
Ram.NOM car drive-IMPF be.PRES
'Ram drives a car.'
b. Ram-ne gari cala-ta (hai).
Ram-ERG car drive-PERF be.PRES
'Ram has driven a/the car.'

Importantly, since neither the difference in prominence between the subject and object nor the qualification of Ram as a driver changes with tense or aspect, it is unlikely that this differential use of case can straightforwardly be explained in terms of distinguishability or markedness (which were said to play a role in (1) and (2)).

Finally, example (7) shows how the use of case is sometimes even dependent on structural position, case concord only taking place if the adjective is separated from its head.

Warlpiri (Hale 1973; cited in Blake 1994, 96)
a. Tyarntu wiri-ngki=tyu
yarlki-rnu.
dog big-ERG=1.SG.OBJ bite-PAST
'The big dog bit me.' 


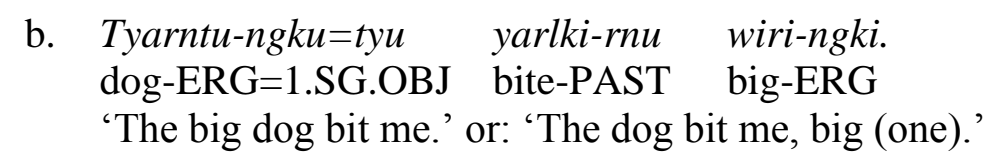

In the next sections, it will be proposed that a uniform account can be given for this, what at first sight may seem rather heterogeneous, collection of case alternations. For that, it will be necessary first to develop a functional understanding of case, as it will be very hard to come up with a satisfying explanation if case is exclusively understood as a structural prerequisite of language structure.

\section{Constraints on the Use and Development of Case (and Language)}

Since it is impossible to capture in language all semantic distinctions that could be made in principle, the speaker has to abstract away from idiosyncratic properties of objects, events, and relations in virtually each utterance. The task for the hearer, subsequently, is to recognize these generalizations and to enrich the semantics of the utterance to arrive at an interpretation close to the intended, particular meaning (cf. Grice, 1989; Levinson, 1983; Haspelmath, 2007). It is proposed here that the use and development of case should be understood in the same light. More importantly for present purposes, the variation in case marking described in the previous section follows naturally from the functional perspective to be sketched here (for a more elaborate discussion, cf. XX1).

As is well-known since the work of Zipf (1965), frequency of use correlates negatively with word length. This correlation can be explained as the result of grammaticalization (cf. for example Lehmann, 1985; Hopper and Traugott, 2003). In this diachronic economization process, in addition to semantic and syntactic changes, the forms of frequently used words become shorter and shorter. For this, two independent motivations can be hypothesized. First, there is the production bottleneck (see Levinson, 2000a,b). Pre-articulation processes have been shown to run faster than the articulation process itself (Anderson, 1982; Wheeldon and Levelt, 1995, 327) and comprehension can handle increased speech rates without any problems (Mehler et al., 1993). Because of this bottleneck, linguistic coding is costly: It slows down the communication process. By shortening frequently used words, the speaker can speed up the communication process most effectively. Second, speaker economy can be considered an important motivation. To save pronunciation effort, words are often expressed imperfectly. Without context helping in reconstructing the target form, this would easily lead to severe problems. But in context, degenerated acoustic signals hardly ever form a problem in understanding (Brouwer, 2010). Eventually, this imperfect pronunciation can lead to a different phonological representation. A younger generation of language learners may "wrongly" store a reduced form of a word (in the examplar-based model of Bybee, 2010, this change may even take place within a single generation of speakers). Words that express general and frequently-used relations between, or properties of, content words can be expected to be especially susceptible to such impoverished inheritance. Because of their general meaning and frequent use they are predictable, and therefore reducible. Indeed, function words are on average much shorter than lexical words.

Morphological case could be considered the ultimate result of such a grammaticalization process. Because of its frequent use, (the predecessor of) case became a suffix, a morpheme that is reduced to the extent that it, according to language-dependent criteria, can no longer be used independently in a sentence but has to be attached to other words. The motivation for the frequent 
use of case and its resulting far-going grammaticalization is that it expresses semantic roles. Semantic roles, it is proposed here, are to be understood as language-specific generalizations about the functions event participants may have in a communicated event. The semantics of the role of an argument in a particular event is much richer but cannot efficiently be communicated as such for all individual participants (for a similar view of the distinction between a rich conceptual and language-ready logical level, cf. amongst many others Levelt 1989, Bierwisch and Schreuder 1992). By categorizing arguments into semantic roles, the speaker can use more economical means of expression, namely the forms corresponding to semantic roles. From the semantics of the predicate, the hearer can tell the precise argument function. For example, the Agent of to hit is a hitter but the Agent of to walk is a walker. Other semantic roles are, for example, Instrument (a thing that is used to achieve something), Theme (a thing that undergoes an action without being changed by it), and Beneficiary (person for whom some action is performed), each of which, if recognized in a language, has a language-particular range of specific functions.

Attractive as they may sound, it is notoriously difficult and a matter of ongoing debate to determine which semantic-role generalizations should be made and how these generalizations should be defined and labeled. Because of this, most linguists agree that semantic roles are a problematic concept (Butt, 2006, 31). The problem is the, arguably, wrong assumption, that semantic roles are universal concepts. Instead, Langacker $(1991,284)$ argues that a definite list is neither necessary nor achievable. Semantic roles are generalizations and languages can differ in the degree they abstract away from the unique semantic properties each verb defines for its participants (cf. also Croft 1991). Thus, semantic roles should not be any more problematic than the notion of words in the lexicon. There is no universal set of semantic roles simply because semantic roles are language-specific generalizations about arguments, just like the lexicon is a set of language-specific generalizations about individual objects and events. The higher the level of generalization, however, the more commonalities we can expect between the categories of different languages (Rosch, 1978). Since the set of general principles that are useful and applied at this level of categorization is restricted, the types of semantic roles that are discerned will be comparable between languages, which probably explains the quest for a universal list of semantic roles. However, the results of categorization do vary between languages and the failure to establish this list can be seen as evidence for the view of semantic roles as language-particular generalizations.

Core cases have grammaticalized even beyond the point of expressing semantic roles. They could be considered to be generalizations about semantic roles, more specifically, about the semantic roles that are used by default in combination with some verb. Core cases are mostly used in combination with transitive predicates, such as hit, see, help, and read, which by definition have two, predicate-specific, prominent event modifiers that are virtually always selected and therefore highly predictable. Similarly to the procedure described above for semantic roles, the exact semantics of this subject and object can be derived from the predicate semantics. Consider the German examples in (8). 
German

a. Der Mann schlug den Jungen
the man hit the boy
'The man hit the boy.'
b. Der Mann sah den Jungen.
the man saw the boy.
'The man saw the boy.'

The semantic functions of the arguments can be described at various levels of generalization. At a low level, in (8-a) the man is a hitter (or even more specifically, a hitter of boys) and the boy is a hittee (by a man) whereas in (8-b) the man is a seeer and the boy someone who is seen. At a medium level, the man is an Agent and a Perceiver, and the boy a Patient and Theme/Stimulus, respectively. At the highest level, the man is a subject and the boy is an object in both sentences. Just like we know that the Agent of 'to hit' is a hitter, we know that the subject of 'to hit' is an Agent, and therefore a hitter, and its object a Patient and hittee (and similarly for 'to see'). Core case can thus be seen as the highest possible generalization about arguments, namely as a two-way classification of the two semantic roles that are default for some specific predicate, on the basis of properties such as animacy, awareness, and control (cf. the proto-argument properties of Dowty, 1991; Hopper and Thompson, 1980; Primus, 2003).

The view on case proposed in this paper (more elaborately discussed in XX1) differs from the standard view in yet another way. Often, most notably in the Chomskyan framework, case is thought of as a crucial output criterion of the language, which needs to be assigned either overtly or covertly. In the perspective proposed here, however, case markers primarily are a service from the speaker to the hearer instead. A speaker does not just use case marking to express their thoughts for herself, they want to communicate these thoughts to a hearer. An utterance is a meaning wrapped in an expression from which the original meaning should be derivable again. Because of time constraints on conversation, this expression should not be too extensive. Together with strategies like word order, prominence and agreement, case is used to aid the hearer in getting the right interpretation while at the same time remaining faithful to an economy principle. Case, and language in general, for that matter, can thus largely be understood in light of its communicative function. Preferably, as much of language structure as possible is explained from such a general functional perspective: the more phenomena can be understood as the result of a diachronic adaptation process, the less ad hoc the linguistic theory. Importantly, this view allows for the possibility of the optional use of case, as we will see in the next section. Note first, however, that this is by no means to deny the fact that the use of case has become obligatory in some of the language systems in which it developed (a result dubbed functional overkill by Durie 1995). Rather, it is meant as a functional motivation for the development of such a structure (cf. also Haspelmath, 1999).

The following three constraints can be distilled of the above discussion. First, ECONOMY asks for economic and succinct expressions. It is a well-established constraint in the functional literature (cf. Grice 1989, Haspelmath 2007), often appearing in more specific formulations to deal with the particular variation of concern. Importantly, however, being faithful to this principle is only made possible by the cooperativeness of the hearer, which can be broken down into two constraints. First, the hearer has to be willing to enrich the utterance proper with those things that need not be 
said because they are easily inferable from linguistic and/or situational context, or from general world knowledge. This principle is captured by the constraint PREDICT (cf. e.g. Levinson 1983, Zwarts 2004). Finally, a third constraint, dubbed FAITHL (cf. Grice 1989, Zeevat 2000), is necessary to cancel unwanted default inferences. The enrichment of the utterance proper with additional information should never go at the cost of what is being said explicitly ${ }^{2}$. As the hearer knows, anything the speaker says is in spite of ECONOMY and should therefore not be ignored.

The constraints and their definitions are summarized in (9).

a. ECONOMY: be economical in expressing what you want to say

b. PREDICT: enrich the utterance proper with any additional information available to predict the precise meaning

c. FAITHL: do not ignore linguistic signs (i.e., interpret the semantic role expressed by a case marker)

In the next section, these constraints will be used to explain the variation of case alternations in Section 2. The general idea will be that in such alternations a form is chosen that is maximally economic and still sufficiently informative. It will be shown that sometimes case is cheapest option, but at some other times it alternates with an even more economic expression, viz. a zero form.

\section{Accounting for the Variation}

The optimization procedure between the speaker's wish to be economical and the requirement for the utterance to be intelligible can be formalized in bidirectional Optimality Theory (bidirectional OT; Blutner et al. 2006). In addition to the standard OT assumption that language rules are violable constraints (Prince and Smolensky, 1993/2004), bidirectional OT evaluates candidates on their communicative qualities. That is, both from a hearer and speaker perspective. The use of case can thus be modelled as a bidirectionally optimal solution for the expression of a meaning.

More specifically, the semi-bidirectional version of OT proposed by de Swart (de Swart, 2007, forthcoming) will be used here. In this version, there is only one meaning for the expression of which in principle only one form is considered. The production of a sentence is constrained by its interpretation. The speaker checks if the optimal candidate from their speaker perspective will indeed lead to the right interpretation. If not, they will resort to a suboptimal form that probably will get the meaning across.

Before showing how this approach concretely applies to case alternations, it is important to be explicit about the scope of the claims to be made. The present proposal aims to motivate the possibility and directionality (i.e., Where does the shorter alternative go?) of the attested case alternations by means of the three general constraints introduced in the previous section. The goal is not to propose that these constraints are all there is to synchronic grammar. Instead, it is hypothesized that from optimization procedures in which such very general constraints play a role, more specific rules of grammar may originate in a process of fossilization (term by Blutner 2007; cf. also Durie 1995; Zwarts et al. 2009; Lestrade 2010, and Hebb's rule). In this process, a bidirectional optimization process becomes standardized into a direct link between an input

\footnotetext{
${ }^{2}$ As is always the case in linguistics, "never" is too strong. If a speaker obviously is confusing things (e.g. saying by turning on the stitch), a cooperative hearer will probably repair the confusion (i.e. interpreting 'by turning on the switch').
} 
meaning and an output form (cf. Section 4.4 below). In this way, rules of grammar develop from the same principles that guide our communication, which is a highly desirable design feature from a functional perspective ${ }^{3}$.

\subsection{Spatial case alternations}

First, consider again the spatial case alternation in Bukharian Uzbek repeated in (10).

Bukharian Uzbek (Aziz Djuraev, p.c.)

$$
\begin{aligned}
& \text { Siz bozor(-ga) borasizmi? } \\
& \text { you market-DAT go } \\
& \text { 'Will you go to the marketplace?' }
\end{aligned}
$$

The corresponding optimization procedure is illustrated in Tableaux 1 and 2. ECONOMY prohibits the use of the dative marker and therefore a zero marked form is always preferred from the perspective of the speaker ${ }^{4}$. However, as (10) shows, this spatial case marker is only optionally omitted. Apparently not all speakers think the Goal function of a market place sufficiently follows from its inherent semantics or the motion context. This is illustrated by the different optimization procedures in the two tableaux. In Tableau 1, which represents the optimization procedure that leads to the zero marked expression, any other interpretation than a Goal role for the market place, only illustrated for the Instrument role here for reasons of space, is considered a violation of PREDICT $\left(\operatorname{INT}_{\mathrm{a}}\right.$ ). Thus, although the case marked candidate would lead to the same interpretation (INT $\mathrm{b}$ ), the zero marked candidate suffices already and becomes bidirectionally optimal, indicated by the two-way arrow that points out the winning candidate.

\begin{tabular}{|c|c|l|l|}
\hline $\begin{array}{l}\text { PROD: Go(e) \& Agent(e,you) \& } \\
\text { Goal(e, market) }\end{array}$ & FAITHL & PREDICT & ECONOMY \\
\hline $\begin{array}{l}\text { a. } \text { market }-\varnothing \\
\text { b. } \text { market } \text {-LOC }\end{array}$ & & & $*$ \\
\hline \hline INT $_{\mathrm{a}}$ market- $\varnothing$ & FAITHL & PREDICT & ECONOMY \\
\hline $\begin{array}{l}\text { market }=\text { Instrument } \\
\rightarrow \quad \text { market }=\text { Goal }\end{array}$ & & $*$ & \\
\hline \hline INT $:$ market-LOC & FAITHL & PREDICT & ECONOMY \\
\hline $\begin{array}{l}\text { market }=\text { Instrument } \\
\text { market }=\text { Goal }\end{array}$ & $*$ & $*$ & \\
\hline \multicolumn{2}{|l|}{ Tableau 1: Optimization procedure of zero marking in Bukharian Uzbek } \\
\hline
\end{tabular}

This procedure contrasts with that in Tableau 2. Again, an unmarked form candidate is preferred from the speaker's perspective, as pointed out by the simple arrow at the production evaluation (PROD). As the evaluation of this candidate shows, however, the speaker thinks context and world knowledge may be insufficient for the hearer to tell the semantic role of the market place (i.e.

\footnotetext{
${ }^{3}$ Note that the present approach thus deviates from standard OT in yet another way: In standard OT, constraints are universally given and languages differ only in their ranking; cf. Haspelmath (1999).

${ }^{4}$ For a more elaborate introduction to bidirectional OT, cf. e.g. Blutner et al. (2006); de Swart (forthcoming); Lestrade (2010).
} 
PREDICT does not apply and no choice can be made between the meaning candidates). As a result, the unmarked form is considered ambiguous and, in spite of ECONOMY, locative case is judged to be necessary to ensure the correct interpretation by FAITHL (INT $)$. Thus, a more marked form becomes optimal, indicated by a two-way arrow.

\begin{tabular}{|c|l|l|l|}
\hline $\begin{array}{l}\text { PROD: Go(e) \& Agent(e,you) \& } \\
\text { Goal(e, market) }\end{array}$ & FAITHL & PREDICT & ECONOMY \\
\hline $\begin{array}{l}\rightarrow \quad \text { a. } \text { market }-\varnothing \\
\text { b. } \text { market } \text {-LOC }\end{array}$ & & & $*$ \\
\hline \hline INT $_{\mathrm{a}}$ market- $\varnothing$ & FAITHL & PREDICT & ECONOMY \\
\hline $\begin{array}{l}\text { market }=\text { Instrument } \\
\text { market }=\text { Goal }\end{array}$ & & & \\
\hline \hline $\begin{array}{l}\text { INT }_{\mathrm{b}} \text { : market-LOC } \\
\text { market }=\text { Instrument } \\
\rightarrow \quad \text { market }=\text { Goal }\end{array}$ & FAITHL & PREDICT & ECONOMY \\
\hline
\end{tabular}

Tableau 2: Optimization procedure of dative marking in Bukharian Uzbek

It is known from the literature that less prototypical performers of some function require a more elaborate encoding for this (cf. Section 1). Whereas this observation originally was restricted to the marking of core argument functions, it has been extended to other domains by, amongst others, Aristar (1996, 1997) and Creissels (2009). For example, (Creissels, 2009, 612-613) observes that geographical names often have a simpler spatial marking than animates. In terms of the present proposal, this means that whenever PREDICT does not apply, FAITHL has to be used to ensure the correct interpretation (cf. Tableau 2).

Two technical notes about the formalization procedure can be made for clarification. In these tableaux a violation of ECONOMY is only registered at the production stage and does not apply to the interpretation evaluation by definition (cf.(9)). The hearer cannot do anything about the length of the utterance they have to interpret, as this is simply given (cf. Zeevat, 2000). Also note that although both form candidates are simultaneously given, in principle only one is considered at a time, and only the one with the double-headed arrow will be produced. If this happens to be the most economical candidate, the marked alternative will not be further considered.

\subsection{Case vs. Postpositions}

The alternation between a spatial case form and a prepositional phrase (or between a case-like economical form and a more elaborate construction) works very similarly to the alternation between a case and a zero form, described in the previous section. The only difference is that in the latter alternation, case was the more economical option, whereas it is the less marked alternative in the present case. Consider the relevant example from Marathi again:

Marathi (Pandharipande 1997, 340)

a. Tsor gharā-t s'irlā.

thief house-LOC entered

'The thief entered the house.' 


\section{b. Tsor gharā-tSyā-àt s'irlā. \\ thief house-PX-in entered \\ 'The thief entered the house.'}

Again, the alternation is only optional and both options are allowed. This means that, apparently, the underspecified spatial case is not always judged to be sufficient to express the inside region of the house. In Tableaux 3 and 4, the optimization processes of the two options are represented. Tableau 3 shows the optimization process if the speaker thinks the inside location sufficiently follows from context and world knowledge. In this case, the more economical option suffices and becomes bidirectionally optimal. (Again, only one meaning alternative is considered here.)

\begin{tabular}{|c|c|c|c|}
\hline PROD: location = house's inside & FAITHL & PREDICT & ECONOMY \\
\hline $\begin{array}{ll}\leftrightarrow \quad \text { a. house-LOC } \\
\quad \text { b. house-PX-in }\end{array}$ & & & $*$ \\
\hline INT $_{\mathrm{a}}$ : house-LOC & FAITHL & PREDICT & ECONOMY \\
\hline $\begin{array}{ll}\rightarrow \quad \text { location }=\text { inside } \\
\text { location }=\text { front }\end{array}$ & & $*$ & \\
\hline $\mathrm{INT}_{\mathrm{b}}$ : house-PX-in & FAITHL & PREDICT & ECONOMY \\
\hline $\begin{array}{ll}\rightarrow \quad \text { location }=\text { inside } \\
\text { location }=\text { front }\end{array}$ & * & 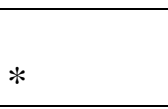 & \\
\hline
\end{tabular}

Tableau 3: Optimization procedure of locative case marking in Marathi

This optimization procedure contrasts with that in Tableau 4. Here, the speaker thinks the inside location does not become sufficiently clear from context. Locative case is judged ambiguous and therefore the more explicit prepositional phrase has to be used.

\begin{tabular}{|c|l|l|l|}
\hline PROD: location $=$ house's inside & FAITHL & PREDICT & ECONOMY \\
\hline $\begin{array}{l}\rightarrow \quad \text { a. } \text { house }- \text { LOC } \\
\leftrightarrow\end{array}$ b. house-PX-in & & & $*$ \\
\hline \hline INT $_{\mathrm{a}}$ house-LOC & FAITHL & PREDICT & ECONOMY \\
\hline $\begin{array}{l}\text { location }=\text { inside } \\
\text { location }=\text { front/roof }\end{array}$ & & & \\
\hline \hline $\mathrm{INT}_{\mathrm{b}}$ : house-PX-in & FAITHL & PREDICT & ECONOMY \\
\hline $\begin{array}{l}\text { location }=\text { inside } \\
\text { location }=\text { front/roof }\end{array}$ & $*$ & & \\
\hline
\end{tabular}

Tableau 4: Optimization procedure of adpositional marking in Marathi

\subsection{Positional case alternations}

We are probably most familiar with languages in which case concord takes place within the noun phrase, as is the case in most Indo-European languages. In another very common type of languages, however, case marking is used only once to mark the entire constituent (Blake, 1994, 99). For example, in (12), accusative case is placed on the final word of the noun phrase 'all human kind' only: 
Kannada (Blake, 1994, 100)

Naanu ellaa maanava janaangavannu priitisutteene.

I.NOM all human community.ACC love.1SG

'I love all humankind.'

In intermediate options of case concord, case marking is obligatory once (for example on the head) and repeated optionally on the dependents (Blake, 1994, 100). Above, we saw an example of such an intermediate type. In Warlpiri, the use of concord case depends on the position of the constituent it marks. If the elements of the constituent are adjacent, only one case form is used (13-a); if they are apart, case concord does take place (13-b).

Warlpiri (Hale 1973; cited in Blake 1994, 96)

$$
\begin{array}{lll}
\text { a. Tyarntu wiri-ngki=tyu } & \text { yarlki-rnu. } \\
\text { dog big-ERG=1.SG.OBJ } & \text { bite-PAST } \\
\text { 'The big dog bit me.' } &
\end{array}
$$

b. Tyarntu-ngku=tyu yarlki-rnu wiri-ngki.

dog-ERG=1.SG.OBJ bite-PAST big-ERG

'The big dog bit me.' or: 'The dog bit me, big (one).'

The intuition about the optimization procedure is probably clear by now. If the function or relation of the constituents is made sufficiently clear by their relative position already, case is unnecessary and can therefore omitted because of economy. The difference between the $a$ and $b$ example is illustrated in Tableaux 5 and 6.

In the first example, analyzed in Tableau 5, the noun and the adjective modifier are put adjacent. From word order then, the hearer can easily tell that they belong to each other (cf. the grouping principle of Jackendoff, 2002), and together fill the roll expressed by the ergative case. Depending on the validity of word order as a cue, one may analyze any other interpretation than 'big dog' as a violation of either FAITHL or PREDICT (cf. the difference between "hard" and "soft"

\begin{tabular}{|c|c|c|c|}
\hline PROD: 'the big dog bit me' & FAITHL & PREDICT & ECONOMY \\
\hline $\begin{aligned} \leftrightarrow & \text { a. } d o g \text { big-ERG me bit } \\
& \text { b. dog-ERG big-ERG me bit }\end{aligned}$ & & & $*$ \\
\hline INT $_{\mathrm{a}}$ : dog big-ERG me bit & FAITHL & PREDICT & ECONOMY \\
\hline $\begin{array}{l}\rightarrow \quad \text { 'the big dog bit me' } \\
\text { 'the dog bit the big me' }\end{array}$ & $*$ & $*$ & \\
\hline $\mathrm{INT}_{\mathrm{b}}: d o g$-ERG $b i g$-ERG $m e$ bit & FAITHL & PREDICT & ECONOMY \\
\hline $\begin{array}{l}\rightarrow \quad \text { 'the big dog bit me' } \\
\text { 'the dog bit the big me' }\end{array}$ & $*$ & & \\
\hline
\end{tabular}
constraints by Bresnan et al., 2001). In any event, word order suffices here to correctly combine the constituents of the nominal phrase. 
Now consider the optimization procedure of the second example in Tableau 6. Here, the constituents are separated as a result of which word order cannot be used to tell their relation. Therefore, without the use of ergative case on the adjective, it would not be clear to which nominal it belongs. By the repeated use of ergative case, the speaker makes sure that the hearer does get the right interpretation. Both constituents belong to the thing with the role expressed by the ergative case.

\begin{tabular}{|c|c|c|c|}
\hline PROD: 'the big dog bit me' & FAITHL & PREDICT & ECONOMY \\
\hline $\begin{array}{ll}\rightarrow & \text { a. dog-ERG me bit big } \\
\leftrightarrow & \text { b. dog-ERG me bit big-ERG }\end{array}$ & & & $*$ \\
\hline INT $_{\mathrm{a}}: d o g$-ERG me bit big & FAITHL & PREDICT & ECONOMY \\
\hline $\begin{array}{l}\text { 'the big dog bit me' } \\
\text { 'the dog bit the big me' }\end{array}$ & & & \\
\hline INT $_{\mathrm{b}}$ d $d o g$-ERG $m e$ bit big-ERG & FAITHL & PREDICT & ECONOMY \\
\hline $\begin{aligned} & \text { 'the big dog bit me' } \\
& \rightarrow \quad \text { 'the dog bit the big me' }\end{aligned}$ & $*$ & & \\
\hline
\end{tabular}

An anonymous reviewer remarked that the interaction between structural position and case marking is more complex, referring to a generalization about agreement impoverishment by Samek-Lodovici $(2002,50)$. There, it is proposed that agreement within local projections is never poorer than agreement within their extended projections. That is, (person, number, gender) agreement only occurs if an agreement trigger occurs within some local projection (spec-head agreement) and therefore may not occur if the trigger is outside of such a projection. Clearly, this generalization describes the very opposite pattern of the one just discussed, in which greater distance leads to overt marking. This difference between case marking and verbal agreement is easily explained, however, when understanding the different functions they have. Givón (1976) argues that subject agreement developed via the grammaticalization of topic coreferential pronouns. In this view, the subject is a grammaticalized topic that has become part of the argument structure of the verb (Li and Thompson 1976; Lehmann 1976; Givón 1976; cf. also the contributions in van Bergen and de Hoop 2009; especially the one by Brunetti). Instead, as discussed above, case markers primarily express semantic roles. Whereas moving the subject out of topic position leads to a situation in which there no longer is a topic to agree with because of which agreement impoverishment is indeed expected; a semantic role may become unclear because of the moving about of constituents, because of which extra case marking is in fact expected.

\subsection{Core vs. spatial case alternations}

Also the alternation between a core and spatial case can be explained in the present framework, although this requires a brief elaboration on the organization of spatial language.

In a typical spatial expression, such as The cup is on the tableau, a movable entity, the locatum, is related to a stable reference object, the ground. Spatial case is mostly used to mark the mode function of the ground, i.e. whether it is a Goal, Source, or Place (sometimes very coarsely further specifying the region with respect to the ground; cf. Talmy 2001, Bateman et al. 2010, and Lestrade 2012 for terminology and further discussion). Since animates are likely to move, they are rather 
infelicitous as a reference object. For a reliable specification of the location of the figure, the speaker better uses a more immovable object. Indeed, in many languages the use of spatial case on animates is either prohibited or in need of additional "bridging morphemes" to make possible the marked combination (Aristar, 1996, 1997).

How could this help us explain the Lezgian use of ablative case to mark the Agent as performing an act involuntarily, repeated in (14)?

Lezgian (Haspelmath 1993, 292)
Zamira-di(-waj) get'e xana.
Zamira-ERG-ABL pot break.AOR
'Zamira broke the pot (accidentally/involuntarily).'

As just said, a spatial case, such as the ablative case, normally marks its bearer as a stable reference object. According to (Dowty, 1991, 576) however, typical Agents are (amongst other things) volitional causers of an event. As a result, the combination of the two cannot be interpreted straightforwardly and a compromise between the two must be sought instead. Rather than changing completely from an animate to an inanimate entity, the animate entity gives up some of its most salient animacy features, preferably the ones that are especially inappropriate in a spatial function. By giving up volitionality, its combination with a spatial case becomes better. The spatial case in turn has to give up its ground function. By thus being (partly) faithful to both the semantics of the animate Agent and that of the spatial case, the hearer arrives at the correct interpretation. The optimization process is represented in Tableau 7. Ergative case is the less marked alternative but does not express involuntariness and hence cannot be used to express the intended meaning of (14). The use of ablative case does work out: Interpreting Zamira as a Ground would be incompatible with her animacy status (and therefore a violation of FAITHL or, at the very least, of PREDICT) but also ignoring the spatial case altogether would be a violation of FAITHL. However, the compromise that can be reached in the way described above does yield the right interpretation of an involuntary Agent ${ }^{5}$.

\begin{tabular}{|c|c|c|c|}
\hline PROD: involuntary Agent(e, Zamira) & FAITHL & PREDICT & ECONOMY \\
\hline $\begin{array}{ll}\rightarrow & \text { a. Zamira-ERG } \\
\leftrightarrow & \text { b. Zamira-ERG-ABL }\end{array}$ & & & $*$ \\
\hline INT $_{\mathrm{a}}:$ Zamira-ERG & FAITHL & PREDICT & ECONOMY \\
\hline $\begin{array}{ll}\rightarrow \quad \text { Agent(e, Zamira }) \\
\text { involuntary Agent(e, Zamira) } \\
\text { Ground(e, Zamira) }\end{array}$ & & $*$ & \\
\hline INT $_{\mathrm{b}}$ : Zamira-ERG-ABL & FAITHL & PREDICT & ECONOMY \\
\hline $\begin{array}{ll} & \text { Agent(e, Zamira }) \\
\text { involuntary Agent(e, Zamira }) & \\
\text { Ground(e,Zamira })\end{array}$ & $*$ & * & \\
\hline
\end{tabular}

\footnotetext{
${ }^{5}$ Note how this account thus gives a semantic motivation for the use of spatial case in the argument domain, which contrasts with "standard" explanations in terms of a difference in markedness only (cf. e.g. de Hoop and Malchukov, 2007, 2008).
} 
There is more that could be said about this alternation. Lezgian has a large paradigm of spatial cases and according to the explanation above, in principle each of them could have been chosen, as each of them would result in a compromise in which volitionality is given up. From this paradigm, however, it is specifically a Source case that is selected to mark the unvolitional Agent, which seems motivated as it crosslinguistically seems to be the standard choice (Palancar, 2002). Agent and Source are metonymically related in that both figure at the beginning of an event, the first as the causer that initiates the event, the second as the starting point of the motion. Since this shared meaning dimenion is maintained in their combination, we can think about the interpretation of the Agent as being involuntary as a compromise indeed ${ }^{6}$.

\subsection{Temporal/aspectual case alternations}

Consider again the use of ergative in dependence of tense and aspect. The interpretation clues that are used by PREDICT in this alternation are provided by the speech setting itself. In particular, if the here and now can be used by the hearer to tell apart the Agent from the Patient, that is, if the hearer in principle can observe the distribution of functions, ergative case is judged superfluous.

In Tableau 8, the semi-bidirectional optimization procedure for (15-a) (repeated from above) is illustrated.

Urdu/Hindi (Woolford, 2007)

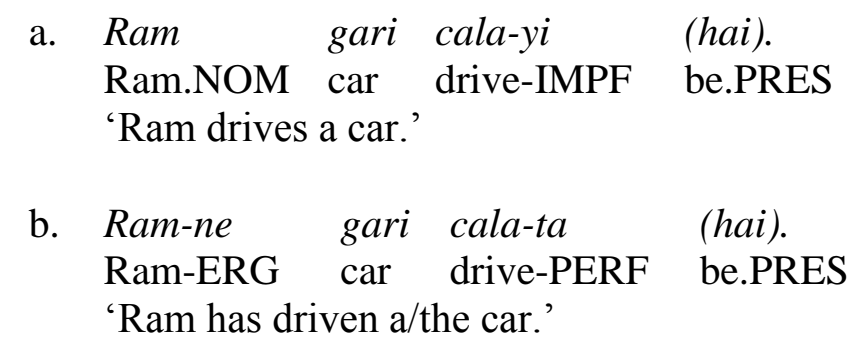

According to Woolford (2007), the primary function of an aspect split is to provide a cheap way of (redundantly) marking aspect. Because the use of case is only blocked for specific aspect levels, e.g. imperfective aspect, the mere presence of case marking provides information about aspect. For very similar alternations in Nepali and Manipuri, Poudel argues that this case alternation can be analyzed in terms of a difference between stage and individual level predication (Poudel, 2007; Butt and Poudel, 2007). Ergative case is used for individual level predication, nominative case is used for stage level predication ${ }^{7}$. Note however that although both accounts may describe the alternation formally, they do not provide a motivation for it.

In XX2, an account is developed in the spirit of the present proposal. The use of ergative case violates ECONOMY, making the first candidate the preferred form. This form indeed will lead to the right interpretation, as its interpretation evaluation shows. On the basis of information available

\footnotetext{
${ }^{6}$ For more fundamental hypotheses concerning the conceptual relation between Source and Agent, cf. Anderson's (1971; 2006) Localist grammar, Hopper and Thompson's $(1980,251)$ characterization of transitivity in terms of "an activity which is carried over or transferred from an agent to a patient", or the discussion in XX1.

${ }^{7}$ Stage level predication says something about the property of a referent that only holds momentarily; individual level predicates predicate an inherent property of a referent.
} 
in the here and now (which use is called for by PREDICT), the agent of the event can be identified. Any other interpretation would violate PREDICT. Also the more marked form would lead to the right interpretation. However, since there is a more economical alternative available already, this candidate is not preferred.

\begin{tabular}{|c|l|l|l|}
\hline PROD: 'Ram drives a car' & FAITHL & PREDICT & ECONOMY \\
\hline$\leftrightarrow \quad$ a. Ram car drive-IMPF & & & \\
b. Ram-ERG car drive-IMPF & & & $*$ \\
\hline \hline INT $_{\mathrm{a}}$ Ram car drive-IMPF & FAITHL & PREDICT & ECONOMY \\
\hline $\begin{array}{l}\text { 'Ram drives a car' } \\
\text { 'he drives Ram's car' }\end{array}$ & & $*$ & \\
'the car drives Ram' & & $*$ & \\
‘.. & & $*$ & \\
\hline \hline INT $_{\mathrm{b}}$ Ram-ERG car drive-IMPF & FAITHL & PREDICT & ECONOMY \\
\hline$\rightarrow \quad$ 'Ram drives a car' & & & \\
'he drives Ram's car' & $*$ & $*$ & \\
'the car drives Ram' & $*$ & $*$ & \\
‘... & $*$ & $*$ & \\
\hline
\end{tabular}

Tableau 8: Optimization procedure of zero marker in Hindi

In Tableau 9, the optimization procedure of (15-b) is illustrated. Again, the zero marked alternative is preferred because of ECONOMY. This time, however, because of the perfective aspect, the here and now does not offer any interpretation clues and the agent function cannot be grounded (i.e. PREDICT does not apply). As a result, the preferred form could be said to be ambiguous and not to straightforwardly lead to the right interpretation. If the speaker wants to make sure that they will be understood, they have to use ergative case, as the interpretation evaluation of the second form candidate shows.

\begin{tabular}{|c|c|c|c|}
\hline PROD: 'Ram has driven a car' & FAITHL & PREDICT & ECONOMY \\
\hline $\begin{array}{ll}\rightarrow & \text { a. Ram car drive-PERF } \\
\leftrightarrow & \text { b. Ram-ERG car drive-PERF }\end{array}$ & & & $*$ \\
\hline $\mathrm{INT}_{\mathrm{a}}$ : Ram car drive-PERF & FAITHL & PREDICT & ECONOMY \\
\hline $\begin{array}{l}\text { 'Ram drives a car' } \\
\text { 'he drives Ram's car' } \\
\text { 'the car drives Ram' } \\
\text { '...' }\end{array}$ & & & \\
\hline INT $_{\mathrm{b}}$ : Ram-ERG car drive-PERF & FAITHL & PREDICT & ECONOMY \\
\hline $\begin{array}{l}\rightarrow \text { 'Ram drives a car' } \\
\text { 'he drives Ram's car' } \\
\text { 'the car drives Ram' } \\
\text { '...' }\end{array}$ & $\begin{array}{c}* \\
* \\
*\end{array}$ & & \\
\hline
\end{tabular}

Tableau 9: Optimization procedure of ergative marker in Hindi

Obviously, other information sources can in principle be used to determine the argument structure. For example, animacy information could be used to rule out the third interpretation option 'the car drives Ram'. Indeed, PREDICT can have this interpretation in other languages (cf. de Swart, 2007; 
Lestrade, 2010). Languages may differ in the way in and the extent to which their grammars make use of this very generally formulated constraint. The speaker makes use of the knowledge of a cooperative hearer (see Grice, 1989; Levinson, 2000b). In the tense/aspect alternations exemplified by Hindi, PREDICT concerns the use of information from the here and now to ground the argument function of an event participant. One may find it hard to believe that a language would not make use of animacy information in such examples. But note that English is an obvious example of a language that does just that. English speakers will interpret the sentence The pie ate the goat with the pie as a (giant cartoon) subject. Instead, Dutch speakers will interpret such a sentence with the goat as the Agent, thereby favoring animacy information over standard word order preferences.

\subsection{Core case alternations}

Let us finally consider the most often cited type of case alternation, repeated in (16) for convenience.

Fore (Scott, 1978, 115-116)
a. Yaga:-wama wá aegúye. pig-ERG man 3SG.OBJ.hit.3SG.SU.IND
'The pig attacks the man.'
b. Yaga: wá aegúye.
pig man 3SG.OBJ.hit.3SG.SU.IND
'The man kills the pig.'

Scott $(1978,114-116)$ argues that ergative case in Fore is used to express deviation from the standard interpretative hierarchy in which higher animates (humans $>$ animates $>$ inanimates) go with higher roles (subject $>$ indirect object $>$ direct object). In case of a draw, linear order is decisive (subjects preceding direct objects). Generally, only when the interpretative hierarchy or linear order needs to be overruled, ergative case -má is used.

In a careful revision of a series of Scott's studies of Fore, Donohue and Donohue (1997) propose a nominative rather than ergative case analysis of the -má marker illustrated in (16), in which the nominative use developed from extending the earlier ergative use. In their analysis, -má is not used to mark an unexpected distribution of roles over two arguments, but rather to mark an unexpected combination of subject role and argument. The distinction between the two types is known as global vs. local DCM. The former type uses the relative properties of both core arguments in deciding about the use of case marking, the latter is only concerned with the appropriateness of a given noun for its argument function irrespective of other clues (cf. Malchukov and de Swart, 2009, 348). ${ }^{8}$

Undisputed examples of global case alternations are easily found in the literature, however. In (17), an example is given of the optional use of the accusative in Awtuw:

\footnotetext{
${ }^{8}$ Probably, local and global DCM are related. The difference between them is in the automatization of the optimization procedure, as will be shown below. Unlike the names suggest, the former could be seen as a generalization of the latter.
} 
Awtuw (de Hoop and Malchukov, 2008, 569)
a. Tey
tale
yaw
daeli.
3FEM.SG woman pig bit
'The woman bit the pig.'
b. Tey tale-re yaw daeli.
3FEM.SG woman-ACC pig bit
'The pig bit the woman.'

According to (de Hoop and Malchukov, 2008, 569), the object is obligatorily marked with accusative case in Awtuw if the object is as high as or higher than the subject in the animacy hierarchy. Generally, subjects are higher in animacy than objects (Comrie, 1981, 128) and if this default pattern applies, case marking is unnecessary in Awtuw (17-a). However, if the object outranks the subject in animacy, the object marker -re has to be used. Note that in these examples it is not the animacy of the arguments per se, but the animacy of the subject in relation to that of the object that determines the case marking. If this animacy relation is unexpected, case marking is necessary.

First consider the OT analysis of global DCM, illustrated by Awtuh. As indicated by the simple arrow at the production evaluation (PROD) in Tableau 10, because of ECONOMY, the zero marked form is preferred from the speaker's perspective. As the interpretation check of this candidate shows, however, the hearer would get the wrong interpretation without the use of accusative case on tale 'woman', see INT $\mathrm{a}$ in Tableau 10. World knowledge would lead them to believe that the woman, not the pig, is the Agent, since humans more often act on animals than the other way around. To overrule this preference, the speaker has to use a slightly more elaborate form, i.e. marking the woman with accusative case. Because of FAITHL, the hearer now arrives at the intended interpretation, as illustrated in the lower part of the Tableau (INT $)$. Thus, in spite of its violation of ECONOMY, the accusative case-marked candidate is found bidirectionally optimal, indicated by the two-way arrow.

\begin{tabular}{|c|c|c|c|}
\hline $\begin{array}{l}\text { PROD: bite(e) \& Agent(e, pig) \& } \\
\text { Patient(e, woman) }\end{array}$ & FAITHL & PREDICT & ECONOMY \\
\hline $\begin{array}{ll}\rightarrow & \text { a. pig- } \emptyset, \text { woman- } \varnothing \\
\leftrightarrow & \text { b. pig- } \emptyset, \text { woman-ACC }\end{array}$ & & & $*$ \\
\hline $\mathrm{INT}_{\mathrm{a}}:$ pig- $\varnothing$, woman- & FAITHL & PREDICT & ECONOMY \\
\hline $\begin{array}{ll}\rightarrow \quad & \text { Agent(e, woman }) \\
& \text { Agent(e, pig) } \\
\end{array}$ & & $*$ & \\
\hline $\mathrm{INT}_{\mathrm{b}}$ : pig- $\varnothing$, woman-ACC & FAITHL & PREDICT & ECONOMY \\
\hline $\begin{aligned} & \text { Agent(e, woman }) \\
\rightarrow \quad & \text { Agent }(e, \text { pig })\end{aligned}$ & $*$ & $*$ & \\
\hline
\end{tabular}

Now let us consider the optimization procedure of (17-b): 'The woman bites the pig'. The crucial difference between Tableau 10 and Tableau 11 is that there now is one form candidate that is optimal from both a unidirectional and bidirectional perspective. Both form candidates lead to the same correct interpretation result, and because of that the more economical version can be chosen. 
The addition of accusative case would not change the meaning and therefore is forbidden by ECONOMY. In the first tableau, contrastively, the use of case was necessary to express a meaning that would otherwise not be conveyed.

\begin{tabular}{|c|c|c|c|}
\hline $\begin{array}{l}\text { PROD: bite(e) \& Agent(e, woman) \& } \\
\text { Patient(e, pig) }\end{array}$ & FAITHL & PREDICT & ECONOMY \\
\hline $\begin{array}{ll}\leftrightarrow \quad \text { a. woman- } \varnothing, \text { pig- } \varnothing \\
& \text { b. woman-ACC, pig- } \varnothing\end{array}$ & & & $*$ \\
\hline $\mathrm{INT}_{\mathrm{a}}:$ woman- $\varnothing$, pig- $\varnothing$ & FAITHL & PREDICT & ECONOMY \\
\hline $\begin{array}{ll}\rightarrow \quad & \text { Agent }(\mathrm{e}, \text { woman }) \\
& \text { Agent }(\mathrm{e}, \mathrm{pig}) \\
\end{array}$ & & $*$ & \\
\hline $\mathrm{INT}_{\mathrm{b}}$ : woman- $\varnothing$, pig-ACC & FAITHL & PREDICT & ECONOMY \\
\hline $\begin{array}{l}\text { Agent }(e, \text { woman }) \\
\text { Agent }(e, \text { pig })\end{array}$ & $*$ & $*$ & \\
\hline
\end{tabular}

Recall from above that differently from the global pattern just illustrated, in which the relative properties of both core arguments are used in deciding about the use of case marking, in local DCM, such as in Fore, only the appropriateness of a given noun for its argument function is considered. This strategy can easily be accounted for by the use of a constraint that requires atypical arguments to be marked (for our ergative language, NONHUMANAGENT $\rightarrow$ ERG, or NHA $\rightarrow$ ERG for shortness). Fortunately, we do not simply have to stipulate its existence, but we can hypothesize that it developed from the generalization about input-output mappings of optimization procedures such as in Tableau 10. If it frequently turns out that atypical arguments cause confusion and therefore need to be marked, a direct link between atypical meaning and marked form can be derived. As a result, the unmarked form will no longer be considered for this kind of meaning input, and the interpretation check showing that the unmarked form does not suffice can thus be bypassed.

When we add this constraint to our constraint set, the Fore pattern is straightforwardly described. First consider the optimization procedure for a nonhuman Agent in Tableau 12.

\begin{tabular}{|c|c|c|c|c|}
\hline $\begin{array}{l}\text { PROD: Attack(e) \& Agent(e, pig) \& } \\
\text { Patient(e, man) }\end{array}$ & $\mathrm{NHA} \rightarrow \mathrm{ERG}$ & FAITHL & PREDICT & ECONOMY \\
\hline $\begin{array}{ll} & \text { a. pig- } \varnothing, \text { man- } \varnothing \\
\leftrightarrow & \text { b. pig-ERG, man- } \varnothing \\
\end{array}$ & $*$ & & & $*$ \\
\hline INT $_{a}$ : pig-ERG, man- $\varnothing$ & $\mathrm{NHA} \rightarrow \mathrm{ERG}$ & FAITHL & PREDICT & ECONOMY \\
\hline $\begin{array}{ll} & \text { Agent }(\mathrm{e}, \text { man }) \\
\rightarrow \quad & \text { Agent }(\mathrm{e}, \text { pig }) \\
\end{array}$ & & $*$ & * & \\
\hline $\mathrm{INT}_{\mathrm{b}}:$ pig- $\varnothing$, man- $\varnothing$ & $\mathrm{NHA} \rightarrow \mathrm{ERG}$ & FAITHL & PREDICT & ECONOMY \\
\hline $\begin{array}{ll}\rightarrow \quad \operatorname{Agent}(\mathrm{e}, \text { man }) \\
\\
\text { Agent }(\mathrm{e}, \mathrm{pig})\end{array}$ & & & * & \\
\hline
\end{tabular}

Tableau 12: Optimization of ergative case in Fore

Given a nonhuman Agent, the unmarked form is excluded by our newly developed constraint and the ergative-case marked form becomes optimal from a production perspective, in spite of its 
violation of ECONOMY. As it correctly leads to the intended meaning, it is found bidirectionally optimal too.

In the second optimization, illustrated in Tableau 13, the zero marked candidate satisfies NHA $\rightarrow$ ERG vacuously, as the constraint does not apply to human Agents. Because of PREDICT, there is no need to check a more marked form: The unmarked candidate will yield the intended meaning already.

\begin{tabular}{|c|c|c|c|c|}
\hline $\begin{array}{l}\text { PROD: Kill(e) \& Agent(e, man) \& } \\
\text { Patient(e, pig) }\end{array}$ & $\mathrm{NHA} \rightarrow \mathrm{ERG}$ & FAITHL & PREDICT & ECONOMY \\
\hline $\begin{array}{ll}\leftrightarrow & \text { a. man- } \varnothing, \text { pig- } \varnothing \\
& \text { b. man-ERG, pig- } \varnothing\end{array}$ & & & & $*$ \\
\hline $\mathrm{INT}_{\mathrm{a}}: \operatorname{man}-\varnothing$, pig- $\varnothing$ & $\mathrm{NHA} \rightarrow \mathrm{ERG}$ & FAITHL & PREDICT & ECONOMY \\
\hline $\begin{array}{ll}\rightarrow \quad & \text { Agent }(\mathrm{e}, \text { man }) \\
& \text { Agent }(\mathrm{e}, \mathrm{pig})\end{array}$ & & & * & \\
\hline INT $_{\mathrm{b}}$ : man-ERG, pig- $\varnothing$ & $\mathrm{NHA} \rightarrow \mathrm{ERG}$ & FAITHL & PREDICT & ECONOMY \\
\hline $\begin{array}{ll}\rightarrow \quad & \text { Agent }(\mathrm{e}, \text { man }) \\
& \text { Agent }(\mathrm{e}, \mathrm{pig}) \\
\end{array}$ & & & $*$ & \\
\hline
\end{tabular}

Tableau 13: Optimization process of zero marker in Fore

\section{Discussion}

By means of three general constraints, a uniform account can be given for a variety of case alternations. However, as was stressed several times from the outset, some of the discussed optimization procedures are likely to have become standardized routines over time. Arguably, there is a trade-off between a real-time calculation of (a solution to) possible ambiguity and the use of a generalized rule that frees the speaker from checking, but necessarily results in accidental unnecessary uses of a structure from a purely communicative perspective (cf. Durie1995 for an informal discussion of this trade-off and its resulting functional overkill, which, it is argued there, cannot be used as an argument against a functional motivation; cf. Pawley 2011, 36 for a discourse illustration with narrative serial verb constructions in Kalam). In some cases, such as the alternation in Uzbek, the choice between a case form and some alternative construction really seems to be a real-time, pragmatically motivated decision. In many other cases, however, the proposed constraints are maybe better understood as communicative guiding principles from which more specific rules of grammar that directly state that some case must be used in some context, for some meaning, or for some arguments have derived. The development of these more specific constraints can be thought of as the result of a process of fossilization in which decisions that once were made frequently have become automatized. This process was illustrated above in the discussion of local DCM in Fore.

Another alternation in which most probably a fossilized constraint is involved is the one driven by specificity in Hindi, repeated in (18). 
Hindi (de Hoop and Malchukov, 2008, 576)

a. Wo ek laD.kaa dekhtaa hae
he one boy seeing is
'He sees a boy.'
b. Wo ek laD.ke-ko dekhtaa hae
he one boy-ACC seeing is
'He sees the boy.'

It can be hypothesized that because of the recurrent need to explicitly mark prominent participants as objects to keep them apart from subjects, an automatized rule of grammar has developed in Hindi that says to simply mark all specific objects, even in the absence of possible confusion.

In conclusion, existing analyses of differential case marking are much too narrowly focused to account for the large variety of case alternations that can easily be identified cross-linguistically. The present proposal, instead, gives a uniform account of this variation using very general Gricean principles of communication only, viz. economy and cooperativeness. These principles were formalized in a semi-bidirectional optimality theoretic framework in the form of the constraints ECONOMY (be economical in expressing what you want to say), FAITHL (do not ignore linguistic signs, i.e., interpret the semantic role expressed by a case marker), and PREDICT (enrich the utterance proper with any additional information available to predict the particular meaning). It was shown that all case alternations, including traditional examples of differential case marking, could thus straightforwardly be described in terms of semi-bidirectional optimization processes.

\section{References}

Aristar, Anthony R. 1996. The relationship between dative and locative: Kurylowicz's argument from a typological perspective. Diachronica, XIII(2):207-224.

-----. 1997. Marking and hierarchy. Types and the grammaticalization of case markers. Studies in Language, 21(2):313-368.

Bateman, John A., Joana Hois, Robert Ross, and Thora Tenbrink. 2010. A linguistic ontology of space for natural language processing. Articial Intelligence, 174:1027-1071.

van Bergen, Geertje and Helen de Hoop. 2009. Topics cross-linguistically (special theme issue). The Linguistic Review, 26(2/3).

Bierwisch, Manfred and R. Schreuder. 1992. From concepts to lexical items. Cognition,42:23-60. Blake, Barry J.. 1994. Case. Cambridge University Press, Cambridge, 2nd edition.

Blutner, Reinhard. 2007. Optimality theoretic pragmatics and the explicature/implicature distinction. In Noel Burton-Roberts, editor, Advances in pragmatics, pages 45-66, Basingstoke, etc. Palgrave/MacMillan.

Blutner, Reinhard, Helen de Hoop, and Petra Hendriks. 2006. Optimal Communication. CSLI, Stanford.

Bresnan, Joan, Shipra Dingare, and Christopher D. Manning. 2001. Soft constraints mirror hard constraints: Voice and person in English and Lummi. In Proceedings of the LFG '01 Conference. CSLI Publications.

Brouwer, Susanne. 2010. Processing strongly reduced forms in casual speech. $\mathrm{PhD}$ thesis, Radboud Universiteit Nijmegen. 
Brunetti, Lisa. 2009. On the semantic and contextual factors that determine topic selection in Italian and Spanish. The Linguistic Review, 26(2/3):261-290.

Butt, Miriam. 2006. Theories of case. Cambridge University press, Cambridge, UK.

Bybee, Joan. 2010. Language, usage and cognition. Cambridge University Press, Cambridge.

Comrie, Bernard. 1981. Language universals \& linguistic typology. University of Chicago press, Chicago, 2nd edition.

Croft, William. 1991. Syntactic categories and grammatical relations. The cognitive organization of information. University of Chicago press, Chicago and London.

Donohue, Cathryn and Mark Donohue. 1997. Fore case marking.

Dowty, David. 1991. Thematic proto-roles and argument selection. Language, 67(3):547-619.

Durie, Mark. 1995. Towards an understanding of linguistic evolution and the notion ' $\mathrm{X}$ has a function Y'. In Werner Abraham, Talmy Givón, and Sandra A. Thompson, editors, Discourse Grammar and Typology: Papers in Honor of John W.M. Verhaar, pages 275-308.

Givón, Talmy. 1976. Topic, pronoun, and grammatical agreement. In Charles N. Li, editor, Subject and topic, pages 149-188, New York, San Francisco, and London. Academic Press, Inc.

Grice, Paul. 1989. Studies in the way of words. Harvard University Press, Cambridge, Mass. and London.

Haspelmath, Martin. 2007. Pre-established categories don't exist: consequences for language description and typology. Linguistic Typology, 11(1):119-132.

de Hoop, Helen and Andrej Malchukov. 2007. On fluid differential case marking: A bidirectional OT approach. Lingua, 117:1636-1656.

-----. 2008. Case-marking strategies. Linguistic Inquiry, 39(4):565-587.

Hopper, Paul J. and Sandra A. Thompson. 1980. Transitivity in grammar and discourse. Language, 56(2):251-299.

Hopper, Paul J. and Elizabeth Closs Traugott. 2003. Grammaticalization. Cambridge University Press, Cambridge, 2nd edition.

Jackendo, Ray. 2002. Foundations of language: Brain, meaning, grammar, evolution. Oxford University Press, Oxford.

Langacker, R.W. 1991. Descriptive application, volume 2. Stanford University press, Stanford.

Lehmann, Christian. 1985. Grammaticalization: Synchronic variation and diachronic change. Lingua e stile a, XX(3):303-318.

Lehmann, W.P. 1976. From topic to subject in Indo-European. In Charles N. Li, editor, Subject and topic, pages 445-456, New York, San Francisco, and London. Academic Press, Inc.

Lestrade, Sander. 2010. The space of case. Ph.D. thesis, Radboud University Nijmegen.

Levelt, Willem J. M. 1989. Speaking. From intention to articulation. The MIT Press, Cambridge, Massachusetts and London, England.

Levinson, Stephen C. 1983. Pragmatics. Cambridge University Press, Cambridge and New York.

-----. 2000b. Presumptive meanings. The theory of generalized conversational implicature. MIT Press, Cambridge.

Li, Charles N. and Sandra A. Thompson. 1976. Subject and topic: A new typology of language. In Charles N. Li, editor, Subject and topic, pages 457-490, New York, San Francisco, and London. Academic Press, Inc.

Malchukov, Andrej and Peter de Swart. 2009. Differential case marking and actancy variations, pages 339-355. Oxford University Press, Oxford. 
Moravcsik, Edith A.. 2009. The distribution of case. In Andrej Malchukov and Andrew Spencer, editors, The Oxford Handbook of Case, pages 231-245, Oxford and New York. Oxford University Press.

Pawley, Andrew. 2011. Event representation in serial verb constructions. In Jürgen Bohnemeyer and Eric Pederson, editors, Event representation in language and cognition, pages 13-42, Cambridge etc. Cambridge University Press.

Primus, Beatrice. 2003. Protorollen und Verbtyp: Kasusvariaton bei psychischen Verben. In Martin Hummel and Rolf Kailuweit, editors, Semantische Rollen, pages 377-401, Tübingen. Narr.

Prince, A. and P. Smolensky. 1993/2004. Optimality Theory: Constraint interaction in generative grammar. Blackwell, Oxford.

Rosch, Eleanor. 1978. Principles of categorization. In Eleanor Rosch and Barbara B. Lloyd, editors, Cognition and categorization, pages 28-49, Hillsdale, New Jersey. Lawrence Erlbaum.

Vieri Samek-Lodovici. 2002. Agreement impoverishment under subject inversion - a crosslinguistic analysis. In Gisbert Fanselow and Caroline Féry, editors, Resolving Conflicts in Grammars: Optimality Theory in Syntax, Morphology, and Phonology, pages 49-82.

Scott, G. 1978. The Fore language of Papua New Guinea. Pacific Linguistics, Canberra.

de Swart, Peter. 2007. Cross-linguistic variation in object marking. Ph.D. thesis, Radboud University Nijmegen.

-----. Forthcoming. Sense and simplicity: Bidirectionality in differential case marking. In Anton Benz and Jason Mattausch, editors, Bidirectional Optimality Theory, Amsterdam. John Benjamins.

Talmy, L. 2001. Toward a Cognitive Semantics. MIT Press, Cambridge and London.

Woolford, Ellen. 2007. Aspect splits as contextual faithfulness. Manuscript, University of Massachusetts.

Zeevat, Henk. 2000. The asymmetry of Optimality Theoretic syntax and semantics. Journal of Semantics, 17:243-262.

Zipf, George Kingsley. 1965. Human behavior and the principle of least effort. An introduction to human ecology. Hafner publishing company, New York and London.

Joost Zwarts. 2004. Competition between wordmeanings: The polysemy of (A)Round. In Cecile Meier and Matthias Weisgerber, editors, Proceedings of SuB8, pages 349-360, Konstanz. University of Konstanz Linguistics Working Papers.

Joost Zwarts, Lotte Hogeweg, Sander Lestrade, and Andrej Malchukov. 2009. Semantic markedness in gender opposition, blocking and fossilization. Language Typology and Universals, 62(4):325-343.

Author's Contact Information:

Sander Lestrade

Department of Linguistics

Radboud University of Nijmegen

The Netherlands

s.lestrade@let.ru.nl 